www.jmscr.igmpublication.org Impact Factor 5.84

Index Copernicus Value: 71.58

ISSN (e)-2347-176x ISSN (p) 2455-0450

crossref DOI: _https://dx.doi.org/10.18535/jmscr/v5i11.150

\title{
Determinants of Neurological Outcome in Surgically Treated Patients of Pott's Spine
}

\author{
Authors \\ Dr Faran Ahmad, Dr Mohammad Kaif, Dr Tarun Pandey, Dr Deepak Kumar Singh \\ Corresponding Author \\ Dr Mohammad Kaif \\ Email: dr_kaifmohd@yahoo.co.in, Mobile: 9305561546
}

\begin{abstract}
Background: Surgical treatment of Pott's Spine is a controversial issue in view of unpredictable outcome. In present study, we made an attempt to assess the factors that play a role in determining the neurological outcome of surgical intervention.

Materials and Method: $A$ total of 30 patients having undergone surgical intervention for Pott's Spine were included in the study. Demographic, clinical, haematological and radiological profiles were noted. Abscess drainage/Debridement / posterior decompression and stabilization; Radical Debridement and Bone Grafting and Radical Debridement, Bone Grafting, and Instrumentation were the surgical interventions done. All the patients were followed up at least upto 9 months. The outcome was noted as PNR (Partial neurological recovery), NCNR (near complete neurological recovery) and CNR (complete neurological recovery). Data was analyzed using SPSS 21.0.

Results: At final follow up, majority had NCNR (53.3\%), followed by PNR (33.3\%) and CNR (13.3\%) respectively. Illness duration $\leq 3$ months, presence of sphincter disturbance and McCormick Grade III/IV were significantly associated with partial neurological recovery $(p<0.05)$.

Conclusions: The findings of the study indicated that duration of illness and some clinical factors might be associated with poor outcome in surgically treated Pott's spine patients.

Keywords: Pott's spine, Surgical Intervention, Determinants, Neurological recovery.
\end{abstract}

\section{Introduction}

Spinal Tuberculosis (Pott's disease, tuberculous spondylitis) constitutes a significant health burden in developing countries. Malnutrition and poor sanitation are the factors contributing to the spread of the disease. It is said to occur in about $1-2 \%$ of patients with tuberculosis. Skeletal involvement has been reported to occur in approximately $10 \%$ of all patients with extrapulmonary tuberculosis, and half of these patients develop infection within the spinal column. In other words, topographically, spinal tuberculosis constitutes about half the cases of skeletal tuberculosis. It results from an infection of the spinal bone by Mycobacterium tuberculosis bacteria via haematogenous and / or lymphatic spread. This organism may remain dormant in the skeletal system for a long period of time before the disease can be detected. It may involve the paravertebral soft tissues, the vertebral body, epidural space and the interverebral discs ${ }^{1}$. 
Paraplegia due to this non-traumatic myelopathy is a disabling and distressing neurological disorder ${ }^{1}$.

Thoracic and lumbar spines are more commonly affected area and $10-40 \%$ of patients with thoracic spine tuberculosis may get neurological deficit. Early measures are needed to halt the progression of destruction and deformity and especially to prevent and overcome paraplegia. The surgical decompression improves drug penetration and help to establish the diagnosis beyond doubt ${ }^{2}$. However proper selection of drug therapy and operative modalities is needed to optimize functional outcome for each individual case of Pott's disease ${ }^{3}$.

Treatment of spinal tuberculosis remains controversial; some authors have advocated chemotherapy alone whereas others have recommended chemotherapy with surgical intervention. The reports of the Medical Research Council suggested that the overall outcome was the same for both operative and non-operative modality. However, patients with neurologic deficit, abscess, kyphosis or intractable pain require surgery. The advantage of surgical treatment over medical treatment is early ambulation of the patient, early neurologic recovery, and less deterioration of the angle of kyphosis ${ }^{4}$. Clinically, the unsightly residual kyphosis at the end of treatment has been a problem for clinicians and patients. Furthermore, trying to correct an established kyphosis poses much more technically demanding procedure than trying to prevent one. In present study we report the outcome of surgical intervention in cases of Pott's spine and also make an attempt to assess the determinants of poor outcome.

\section{Material and Method}

This prospective study was carried out at the Department of Neurosurgery, Vivekananda Polyclinic and Hospital, Lucknow between May, 2009 and January, 2012. All patients admitted in Department of Neurosurgery, with the diagnosis of Pott's spine and planned to undergo surgery and who were followed up for at least 9 months after surgery were included in the study. The study was approved by the Institutional Ethical Committee and informed consent was obtained from all the patients.

Demographic details of the patients were noted. A complete clinical history of all patients was obtained, local examination, systemic examination, haematological work up were done. Neurological examination was done and neurological status of patients was graded using Modified McCormick scale 5 .

All the patients underwent a thorough radiological assessment. Radiological workup including preoperative X-ray to see for collapse of vertebrae and preoperative measurement of Cobb's angle and preoperative MRI of spine was recorded. The following grading criteria was used:

1. X-RAY

a) X-ray- Grading for collapse of vertebra ${ }^{6}$ -

Grade- 0 (Normal) No collapse

Grade I- $20-25^{\circ}$ (low grade)

Grade II- $25-40^{\circ}$ (high grade)

Grade III- $>40^{\circ}$ (high grade)

b) Cobb's Angle Grading ${ }^{7,8}$

Grade I (mild) - $<30^{\circ}$,

Grade- II (moderate) - 30-60

Grade III (severe) - > $60^{\circ}$

\section{MRI}

Changes observed on MRI were,

- Spinal cord compression

- Soft tissue shadows

- Signal cord intensity changes

- Psoas abscess, bony destruction, edema

MRI changes grading

Grade 1 - Spinal Cord Compression

Grade 2 - Grade $1+$ Soft Tissue shadows

Grade 3 - Grade $2+$ Signal Cord intensity changes Grade 4 -Grade 3+Psoas abscess, Bony destruction, edema

All the patients underwent chemotherapy using Injection Streptomycin and four standard Oral chemotherapeutic drugs(Rifampicin $600 \mathrm{mg} / \mathrm{d}$, Isoniazid $300 \mathrm{mg} / \mathrm{d}$, Ethambatol $15 \mathrm{mg} / \mathrm{kg} / \mathrm{d}$, 
and Pyrazinamide $20-30 \mathrm{mg} / \mathrm{kg} / \mathrm{d}$ ).Total $90 \mathrm{Inj}$ Streptomycin were given. Rest four drugs were continued for 12 months duration and then three drugs for 6 months duration.

The following surgical interventions were done

A. Abscess drainage / Debridement / posterior decompression and stabilization

B. Radical Debridement and Bone Grafting

C. Radical Debridement, Bone Grafting, and Instrumentation.

Assessment of the patients' postoperative condition was based on neurological status. Routine spine $\mathrm{x}$-ray was performed at time of discharge and on follow up. All patients received antituberculous drugs for 18 months duration.

At nine month post-operative interval, the neurological outcome of the patients was noted as follows:

CNR - Complete neurological recovery

NCNR - Near complete Neurological recovery

PNR - Partial Neurological recovery

Statistical Analysis: Data was analyzed using

Statistical Package for Social Sciences, version 21.0. Chi-square and Paired ' $t$ '-test was used. A 'p' value less than 0.05 was considered to indicate a significant change.

\section{Results}

Age of patients ranged from 15-70 years with a mean ( \pm SD) $43.00 \pm 17.65$ years. Majority of patients were aged 40 years or above $(56.7 \%)$, were females $(56.7 \%)$, had clinical onset since $\leq 3$ months $(53.3 \%)$. All the patients complained of back pain, motor weakness and sensory deficit. There were $16(53.3 \%)$ patients with sphincter deficit. Dorsal vertebrae were most commonly involved (86.7\%), however, 3 (10\%) had involvement of cervical vertebra and $1(3.3 \%)$ had involvement of lumbar vertebra. In half the cases $(\mathrm{n}=15 ; 50 \%)$, Radical Debridement, Bone Grafting and Instrumentation was performed whereas in 14 (46.7\%) Radical Debridement and Bone Grafting was done. In one case (3.3\%) abscess drainage/Debridement/Posterior decom- pression and stabilization was performed (Table 1).

Preoperatively, except for 3 patients, all the other patients $(n=27 ; 90 \%)$ had McCormick Grade III/IV, however, postoperatively 21 (70\%) patients had Grade I/II, thus showing a significant change $(\mathrm{p}<0.001)$. In X-ray grade too, there was reduction in Grade II/III cases from $22(73.3 \%)$ to $9(30 \%)$ only (p<0.001). On MRI, preoperatively $27(90 \%)$ cases had Grade III/IV, however, postoperatively only $2(6.7 \%)$ patients had Grade III/IV $(p<0.001)$. Preoperatively Cobb's angle ranged from 12 to $45^{\circ}$ with a mean value of $25.59 \pm 7.44^{\circ}$ which increased to range from 21 to $50^{\circ}$ postoperatively with a mean value of $28.72 \pm 6.92^{\circ}$ $(\mathrm{p}<0.001)$ (Table 2).

The final outcome after 9 months follow up was complete neurological recovery (CNR) in 4 (13.3\%) patients and near complete neurological recovery (NCNR) in $16(53.3 \%)$. A total of 10 (33.3\%) cases had only partial neurological recovery (PNR) (Table 3).

On evaluating the role of clinicodemographic profile with final outcome, no significant association of neurological outcome was observed with age, gender, level of involvement, type of surgical procedure performed, X-ray grade, Cobb's angle grade and MRI grade $(p>0.05)$, however, duration of illness $\leq 3$ months, presence of sphincter disturbance and higher McCormick grades (Grade III/IV) were found to be associated with NCNR and PNR $(\mathrm{p}<0.05)$ (Table 4). 
Table 1: Demographic and Clinical of Patients at enrolment

\begin{tabular}{|c|c|c|}
\hline Characteristics & No & Percentage \\
\hline \multicolumn{3}{|l|}{ Age (yrs): } \\
\hline - $<20 \mathrm{yrs}$ & 3 & $10.0 \%$ \\
\hline - $20-40 \mathrm{yrs}$ & 10 & $33.3 \%$ \\
\hline - $40-60 \mathrm{yrs}$ & 11 & $36.7 \%$ \\
\hline - $>60 \mathrm{yrs}$ & 6 & $20.0 \%$ \\
\hline \multicolumn{3}{|l|}{ Gender: } \\
\hline - Females & 17 & $56.7 \%$ \\
\hline - Males & 13 & $43.3 \%$ \\
\hline \multicolumn{3}{|l|}{ Duration of illness (month): } \\
\hline - $\leq 3$ month & 16 & $53.3 \%$ \\
\hline - $\quad>3$ month & 14 & $46.7 \%$ \\
\hline \multicolumn{3}{|l|}{ Clinical presentation: } \\
\hline - Back Pain (BP) & 30 & $100.0 \%$ \\
\hline - Motor Weakness (MW) & 30 & $100.0 \%$ \\
\hline - $\quad$ Sensory Deficit (SD) & 30 & $100.0 \%$ \\
\hline - $\quad$ Sphincter disturbance (SP) & 16 & $53.3 \%$ \\
\hline \multicolumn{3}{|l|}{ Level of involvement: } \\
\hline - Cervical & 3 & $10.0 \%$ \\
\hline - Dorsal & 26 & $86.7 \%$ \\
\hline - Lumbar & 1 & $3.3 \%$ \\
\hline \multicolumn{3}{|l|}{ Surgery done: } \\
\hline - Abscess drainage/Debridement/ Posterior & 1 & $3.3 \%$ \\
\hline decom - pression and stabilization & 14 & $46.7 \%$ \\
\hline $\begin{array}{l}\text { - Radical Debridement and Bone Grafting } \\
\text { - Radical Debridement, Bone Grafting and } \\
\text { Instrumentation }\end{array}$ & 15 & $50.0 \%$ \\
\hline
\end{tabular}

Table 2: Pre-operative and Post-operative Neurological and Radiological Status

\begin{tabular}{|c|c|c|c|}
\hline Variable & Pre-Op & 9 Month & $\begin{array}{c}\mathrm{p} \\
\text { value }\end{array}$ \\
\hline \multicolumn{4}{|c|}{ Neurological Status (McCormick Grade) } \\
\hline Grade I & $0(0.0 \%)$ & $8(26.7 \%)$ & \multirow[t]{4}{*}{$\mathrm{p}<0.001$} \\
\hline Grade II & $3(10.0 \%)$ & $13(43.3 \%)$ & \\
\hline Grade III & $8(26.7 \%)$ & $9(30.0 \%)$ & \\
\hline Grade IV & $19(63.3 \%)$ & $0(0.0 \%)$ & \\
\hline \multicolumn{4}{|l|}{ X-ray Grade } \\
\hline Grade 0 & $1(3.3 \%)$ & $6(20.0 \%)$ & \multirow[t]{4}{*}{0.006} \\
\hline Grade I & $7(23.3 \%)$ & $15(50.0 \%)$ & \\
\hline Grade II & $14(46.7 \%)$ & $7(23.3 \%)$ & \\
\hline Grade III & $8(26.7 \%)$ & $2(6.7 \%)$ & \\
\hline \multicolumn{4}{|l|}{ MRI Grade } \\
\hline Grade 1 & $0(0.0 \%)$ & $17(56.7 \%)$ & \multirow[t]{4}{*}{$<0.001$} \\
\hline Grade 2 & $3(10.0 \%)$ & $11(36.7 \%)$ & \\
\hline Grade 3 & $10(33.3 \%)$ & $2(6.7 \%)$ & \\
\hline Grade 4 & $17(56.7 \%)$ & $0(0.0 \%)$ & \\
\hline $\begin{array}{l}\text { Mean Cobb's Angle Score } \pm \text { SD } \\
\text { (Range) }(\mathrm{n}=27)\end{array}$ & $\begin{array}{c}25.59 \pm 7.44 \\
(12-45)\end{array}$ & $\begin{array}{c}28.72 \pm 6.92 \\
(21-50) \\
\end{array}$ & $<0.001$ \\
\hline
\end{tabular}

Table 3: Final outcome of patients at admission

\begin{tabular}{|c|c|c|}
\hline Final outcome & No & Percentage \\
\hline CNR & 4 & $13.3 \%$ \\
NCNR & 16 & $53.3 \%$ \\
PNR & 10 & $33.3 \%$ \\
\hline
\end{tabular}


Table 4: Determinants of Final Outcome among patients undergoing surgical intervention for Pott's Disease

\begin{tabular}{|c|c|c|c|c|}
\hline \multirow[t]{2}{*}{ Risk factors } & \multicolumn{3}{|c|}{ Final outcome } & \multirow{2}{*}{$\begin{array}{c}\mathrm{p} \\
\text { value }\end{array}$} \\
\hline & $\begin{array}{l}\mathrm{CNR} \\
(\mathrm{n}=4)\end{array}$ & $\begin{array}{l}\text { NCNR } \\
(\mathrm{n}=16)\end{array}$ & $\begin{array}{c}\text { PNR } \\
(\mathrm{n}=10)\end{array}$ & \\
\hline \multicolumn{5}{|l|}{ Age: } \\
\hline$<20 \mathrm{yrs}$ & $2(50.0 \%)$ & $1(6.3 \%)$ & $0(0.0 \%)$ & 0.156 \\
\hline $20-40 \mathrm{yrs}$ & $1(25.0 \%)$ & $6(37.5 \%)$ & $3(30.0 \%)$ & \\
\hline $40-60 \mathrm{yrs}$ & $1(25.0 \%)$ & $6(37.5 \%)$ & $4(40.0 \%)$ & \\
\hline$>60 \mathrm{yrs}$ & $0(0.0 \%)$ & $3(18.8 \%)$ & $3(30.0 \%)$ & \\
\hline \multicolumn{5}{|l|}{ Gender: } \\
\hline Females & $2(50.0 \%)$ & $8(50.0 \%)$ & $7(70.0 \%)$ & 0.581 \\
\hline Males & $2(50.0 \%)$ & $8(50.0 \%)$ & $3(30.0 \%)$ & \\
\hline \multicolumn{5}{|l|}{ Duration of illness: } \\
\hline$\leq 3$ month & $4(100.0 \%)$ & $6(31.3 \%)$ & $7(70.0 \%)$ & 0.021 \\
\hline$>3$ month & $0(0.0 \%)$ & $11(68.8 \%)$ & $3(30.0 \%)$ & \\
\hline \multicolumn{5}{|l|}{ Clinical presentation: } \\
\hline $\mathrm{BP}, \mathrm{MW}, \mathrm{SD}$ & $4(100.0 \%)$ & $8(50.0 \%)$ & $2(20.0 \%)$ & 0.024 \\
\hline BP, MW, SD,SP & $0(0.0 \%)$ & $8(50.0 \%)$ & $8(80.0 \%)$ & \\
\hline \multicolumn{5}{|l|}{ Level of involvement: } \\
\hline Cervical & $1(25.0 \%)$ & $2(12.5 \%)$ & $0(0.0 \%)$ & 0.525 \\
\hline Dorsal & $3(75.0 \%)$ & $13(81.3 \%)$ & $10(100.0 \%)$ & \\
\hline Lumbar & $0(0.0 \%)$ & $1(6.3 \%)$ & $0(0.0 \%)$ & \\
\hline \multicolumn{5}{|l|}{ Surgery done: } \\
\hline $\begin{array}{l}\text { Abscess drainage /Debrideme- nt/ Posterior } \\
\text { decompression and stabilization }\end{array}$ & $0(0.0 \%)$ & $1(6.3 \%)$ & $0(0.0 \%)$ & 0.758 \\
\hline Radical Debridement and Bone Grafting & $2(50.0 \%)$ & $6(37.5 \%)$ & $6(60.0 \%)$ & \\
\hline $\begin{array}{l}\text { Radical Debridement, Bone Grafting and } \\
\text { Instrumentation }\end{array}$ & $2(50.0 \%)$ & $9(56.3 \%)$ & $4(40.0 \%)$ & \\
\hline \multicolumn{5}{|l|}{ MC Cormick Grade: } \\
\hline Low Grade (I \& II) & $2(50.0 \%)$ & $1(6.3 \%)$ & $0(0.0 \%)$ & 0.014 \\
\hline High Grade (III \& IV) & $2(50.0 \%)$ & $15(93.8 \%)$ & $10(100.0 \%)$ & \\
\hline \multicolumn{5}{|l|}{$\mathrm{X}$-ray grade for collapse of vertebra: } \\
\hline Low grade $(0 \& 1)$ & $2(50.0 \%)$ & $4(25.0 \%)$ & $2(20.0 \%)$ & 0.506 \\
\hline High grade $(2 \& 3)$ & $2(50.0 \%)$ & $12(75.0 \%)$ & $8(80.0 \%)$ & \\
\hline \multicolumn{5}{|l|}{ Cobb's Angle Grade: } \\
\hline$<30$ deg & $2(100.0 \%)$ & $7(50.0 \%)$ & $6(66.7 \%)$ & 0.227 \\
\hline$>30 \mathrm{deg}$ & $0(0.0 \%)$ & $7(50.0 \%)$ & $3(33.3 \%)$ & \\
\hline \multicolumn{5}{|l|}{ MRI evaluation: } \\
\hline Low Grade (Grades I\& II) & $3(75.0 \%)$ & $10(62.5 \%)$ & $4(40.0 \%)$ & 0.387 \\
\hline High Grade (Grades III \& IV) & $1(25.0 \%)$ & $6(37.5 \%)$ & $6(60.0 \%)$ & \\
\hline
\end{tabular}

\section{Discussion}

In present study, the average age of patients presenting with Pott's spine was 43 years. Our youngest patient was a 15 years old male child and oldest patient was a 70 years old female. The age profile of patients in present study was similar to that reported by Owolabi et al (2010) ${ }^{1}$ and Gokce et al $(2012)^{7}$, who reported an average age of 41.3 and 39.2 years respectively and an age range of 15 to 70 years and 22 to 76 years respectively. The age profile of present study confirmed that spinal tuberculosis is primarily a disease of adults 9 .

With respect to gender, females slightly outnumbered males (56.7\% vs $43.3 \%)$. This high proportion of females could be associated with low socio- economic class, poor nutritional status and unhygienic living conditions of women who primarily were housewives and hence were more vulnerable to tuberculosis. Similar to present 
study, Akinyoola et al (2007) ${ }^{10}$ and Gokce et al $(2012)^{7}$ in their studies also found spinal tuberculosis to be more common in females (51.02\% and $51.85 \%$ respectively) as compared to males (48.97\% and $48.14 \%$ respectively).

A sizeable proportion of patients in present study (46.7\%) had onset of disease for $>3$ months, thus showing a general lack of awareness regarding signs and symptoms of disease which are responsible for late reporting and deterioration to more severe grades of disease. This delay in presentation was also responsible for presentation with multiple complaints and a poorer neurological status of the patients.

In present study, dorsal spine (86.7\%) was most commonly involved followed by cervical $(10.0 \%)$ and lumbar (3.3\%) spine. Dorsal spine is commonly involved as it is less vascularised than cervical and lumbosacral spine. This finding was in accordance with the findings of Owolabi et $\mathrm{al}^{1}$ and et $\mathrm{al}^{11}$, who in their studies also found that most of the patients had involvement of dorsal spine.

In present study, all the patients received chemotherapy prior to surgery. Surgeries were primarily done for stabilization of spine to prevent progression of kyphosis and not for correction of kyphosis. Surgeries that the patients underwent were: a) Abscess drainage / Debridement/ posterior decompression and stabilization, b) Radical Debridement and Bone Grafting, c) Radical Debridement, Bone Grafting, and Instrumentation (interbody screws and rod). Most common surgical procedure in the present study was Radical Debridement, Bone Grafting and Instrumentation which was performed in 15 patients $(50.0 \%)$ followed by Radical Debridement and Bone Grafting performed in 14 patients (46.7\%) and Abscess drainage/Debridement/ posterior decompression and stabilization in one patient $(3.3 \%)$. Radical debridement and intervertebral grafting [bone graft/ cage (cage filled with iliac crest/rib graft)] was done with the aim to prevent postoperative late kyphosis in Pott's disease. Anterior decompression by preserving the pleura (extrapleural approach) was the preferred method in the thoracic spine. In the lumbar spine posterior decompression and stabilization was done while interbody fusion was performed in both thoracic and the lumbar regions. In 15 out of 30 patients, internal fixation accompanied anterior decompression and intervertebral grafting. The aim of instrumentation was to enhance anterior spinal stability. Graft destruction and a late increase in kyphosis were reduced by this means. Patients in whom radical debridement with only bone grafting was done presented with a more severe deterioration of Cobb's angle as compared with the patients in whom radical debridement with bone grafting/ cage grafting and instrumentation was done. This was because, with bone grafting alone, osteolysis of bone occurs over the period of time thereby increasing the Cobb's angle.

In present study, neurological outcome was outstanding showing migration of $60 \%$ patients with higher McCormick grades (III/IV) to lower grades (I/II). This finding is in agreement with the observation of Nambiar et al. ${ }^{49}$, who also reported that McCormick grades show a significant change following surgical intervention.

Radiological outcome (both X-ray and MRI) also showed a significant reduction from more severe to less severe grades and a significant increase in Cobb's Angle. Similar to results of present study, some other workers ${ }^{7,8,12,13}$, who surgically intervened for correction of kyphosis also showed a significant increase in Cobb's angle.

In present study, at final evaluation (i.e. after 9 months), the final outcome of most of the patients, i.e 16 patients was NCNR (53.3\%) followed by PNR, 10 patients $(33.3 \%)$ and CNR the least, 4 patients $(13.3 \%)$. Thus, in the present study, at final evaluation, 20 patients $(66.67 \%)$ had favourable outcomes (i.e 16 patients with NCNR and 4 patients with $\mathrm{CNR}$ ), while 10 patients (33.33\%) had unfavourable outcomes (PNR). This was similar to the findings of the study of $\mathrm{Su}$ et $\mathrm{al}^{11}$ who mentioned that at the end of follow-up period, the outcome for 37 patients were evaluated 
and Twenty-six patients (70.3\%) had a favourable outcome and $11(29.7 \%)$ had an unfavourable outcome.

The present study showed that the most favourable outcome "CNR" was higher among lower age (<20 yrs) group (50.0\%), involvement of Dorsal spine $(75.0 \%)$, low grade $(<30 \mathrm{deg})$ Cobb's angle $(66.7 \%)$ and low grade MRI compression $(75.0 \%)$; but none of the variable was found to be associated significantly ( $p>0.05)$ with the most favourable outcome. The present study showed that duration of illness $\leq 3$ months, presence of sphincter disturbance and higher McCormick grades (Grade III/IV) were found to be associated with poor outcome (NCNR, PNR). There are limited studies evaluating the association of final outcome with different demographic and clinical predictors. In one such study, Su et al. ${ }^{11}$ showed older age, more severe limb weakness, incontinence, spinal kyphotic deformity and spinal cord compression to be significantly associated with unfavourable outcome, thus showing that demographic and clinical parameters play a role in predicting the outcome in patients of Pott's disease undergoing surgical intervention.

\section{Conclusion}

The findings of present study were interesting and provided an insight into clinical profile, management protocol and treatment outcome in patients of Pott's spine at our facility. The findings also showed that demographic and clinicoradiological profile of patient can play a significant role in predicting and modulating the outcome of surgical intervention. There is limited literature on this aspect, hence, further studies are recommended to explore newer dimensions and to come up with better predictive models.

\section{References}

1. Owolabi LF, Nagoda MM, Samaila AA, Aliyu I. Spinal tuberculosis in adults: A study of 87 cases in Northwestern Nigeria. Neurology Asia 2010; 15(3) : 239- 244.
2. Hodgson AR, Stock FE. Anterior spinal fusion for the treatment of tuberculosis of the spine. J Bone Joint Surg1960; 42A: 295-310.

3. Khoo LT, Mikawa K, Fessler RG. A surgical revisitation of Pott distemper of the spine. Spine J 2003; 3(2):130-145.

4. Medical Research Council Working Party on Tuberculosis of the Spine. A controlled trial of anterior spinal fusion and debridement in surgical management of tuberculosis of the spine in patients on standard chemotherapy. A study in Hong Kong B J Surg1974, 611:853 -866.

5. Manzano G, Green B, Vanni S, Levi AD. Contemporary management of adult intramedullary spinal tumors-pathology and neurological outcomes related to surgical resection. Spinal Cord 2008; 46: 540-546.

6. Bashir U. Osteoporotic spinal compression fracture. Available at: https://radiopaedia.org/articles/osteoporoti c-spinal-compression-fracture. last accessed on 5th April, 2017.

7. Gokce A, Ozturkmen Y, Mutlu S, Gokay NS, Tonbul M, Caniklioglu M. The role of debridement and reconstruction of sagittal balance in tuberculous spondylitis. Indian J Orthop. 2012 ;46(2):145-9.

8. Laopakdee P. Anterior Radical Debridement and Interbody Arthrodesis with Strut Grafting Without Instrumentation for Treatment of Thoracolumbar Spinal Tuberculosis. Khon Kaen Medical Journal 2010; 34 ( 2): 27-32.

9. Lifeso RM, Weaver P, Harder EH. Tuberculous spondylitis in adults. $\mathrm{J}$ Bone Joint Surg Am.1985;67(9):1405-13.

10. Akinyoola AL, Adegbehingbe OO, Ashaleye CM. Tuberculosis Of The Spine In Nigeria: Has Anything Changed? The Internet Journal of Third World Medicine. 2007; 4 (1). 
11. Su SH, Tsai WC, Lin CY, Lin WR, Chen TC, Lu PL, Huang PM, Tsai JR, Wang YL, Feng MC, Wang TP, Chen YH. Clinical features and outcomes of spinal tuberculosis in southern Taiwan. J Microbiol Immunol Infect. 2010; 43(4): 291-300.

12. Jain AK, Dhammi IK, Jain S, and Mishra P. Kyphosis in spinal tuberculosis Prevention and correction. Indian $\mathbf{J}$ Orthop. 2010; 44(2): 127-136.

13. Jain AK, Maheshwari AV, Jena S. Kyphus correction in spinal tuberculosis. Clin Orthop Relat Res. 2007;460:117-23. 